\title{
Manchester Triage System in Primary Health Care: a New Hosting Way?
}

\author{
Danielle de Araújo Moreira1, Hanna Beatriz Bacelar Tibães², Renata Cristina Rocha Batista ${ }^{3}$, \\ Cecília Maria Lima Cardoso ${ }^{4}$, Camila da Silveira Santos ${ }^{5}$, Maria José Menezes Brito 5
}

\section{Abstract}

Background: The Manchester Triage System is considered a breakthrough in the Brazilian health system. However, to use it with resoluteness and legitimacy, it is essential that professionals and managers reflect on the work process at each point of the health care network. The aim of this article was to analyze the Manchester Triage System as a host strategy in the context of primary health care.

Methods and Findings: It is a qualitative research whose study scenario was the primary health care of a municipality in the metropolitan region of Minas Gerais. The participants were 22 professionals. Data were collected through semi-structured interviews between March and May 2014. The answers were submitted to content analysis technique proposed by Bardin. The results showed that the use of the Manchester Triage System in primary care interferes with the creation of bonds, equity of care and the actions recommended at this point of the health care network. A limitation of the study is the fact that professional only from one municipality of Minas Gerais have been investigated.

Conclusions: It is concluded that the time of screening can only set up on an opportunity to humanized meeting and gather information that can support the full and continuous attention when professionals can articulate the use of hard technologies with the use of soft technologies in daily work. More research was needed to contribute to the understanding of the applicability of the STM in the PHC and on the necessary adaptations to that assistance to urgencies and emergencies occur and resolution to reduce the influence on daily practices of professionals and ensure the continuous, comprehensive care to patients.

1 Departamento de enfermagem aplicada. Federal University of Nursing School Minas Gerais. Belo Horizonte, Minas Gerais, Brasil.

2 2Department of Nursing applied. Federal University of Minas Gerais Nursing School. Belo Horizonte, Minas Gerais, Brazil.

3 Federal University of Minas Gerais. Belo Horizonte, Minas Gerais, Brazil.

4 FCV-Sete Lagoas. Sete Lagoas, Minas Gerais, Brazil.

5 Department of Nursing applied. Federal University of Minas Gerais Nursing School. Belo Horizonte, Minas Gerais, Brazil.

Contact information:

Danielle de Araújo Moreira.

”danimg12@yahoo.com.br

Keywords

Primary Health Care; Host; Screening. 


\section{Introduction}

The Primary Health Care (PHC) has been configured as a strategy for reorienting the care model, aiming to design a universal, integrated system [1] with the attention focused on the individual and families ensuring regionalized, continuous and systematic care.

To consolidate the objectives established by the Unified Health System, the Ministry of Health launched in 2003, the National Humanization Policy. This policy aims to integrate the principles of universality, equity, and integrity to the practice of workers and managers, as well as promoting effective actions regarding the care provided to the user in the $\mathrm{PHC}$ and other health care points [2].

The National Humanization Policy proposes changes in care and health management practices, especially through hosting guideline and its devices. It is known that this guideline can be used from two perspectives; the first one against technical, benefiting the building of ethical relationships, responsible and affectionate; and the second understood as technical-assistance action, providing changes in work processes, through analysis and interventions in the relationship, whether between health professionals, between professionals and patients or between patients and their social issue [3].

In this context, the hosting for patients of the health services, reverses the logic of traditional and timely screening for a responsible assistance, able to provide not only a meeting but to create bond opportunities. The hosting is also configured as an occasion to guide the patient to other health services that can contribute to solving demands and strengthening the integrity and continuity of care. The act of hosting is recognized as one care enhancer, and goes beyond the "qualified screening" or "interested listening", being able to provide identification, coping and problem-solving [4].

In this perspective, health plans should be constructed, taking as its premise the co-responsibility, effective communication between professionals and service's patients, the relationship between the Health Care Network, and the efficiency of the reference and counter-reference systems [5]. To organize the service proposed by Health Care Network, it is essential to reinforce the responsibility of PHC professionals in hosting the emerging demands [6-7].

Based on this and in order to ensure that all citizens with urgent and emergency needs are met in accordance with the gravity contributing to the resolution and the strengthening of the bond between the people and the staff [8], the Secretary of Health State of Minas Gerais decided to create a qualifying risk screening by the Manchester Triage System (STM) in all units for the health in the state.

Despite the justification presented for the implementation of the STM in primary care in the state, it is important to reflect on the applicability of the protocol at this point of the health care network, given its peculiarities and the need to approach aspects that go beyond the logic of complains-behavior. It is assumed that in the PHC there is supply of actions for sustainable care in hosting and qualified listening, with humanized service and resolving to population [9].

When considering that the PHC professionals should use the STM, it is essential to reflect on its recent inclusion in primary care, the specific attention to the emergency room at this point in Health Care Network and the shortage of athematic related research in focus. Thus, the question is: Has the Manchester Triage system been constituted as a coherent care strategy with the logic of Primary Health Care?

Based on this question, the aim of this study was to analyze the Manchester Triage System as a hosting strategy in the context of primary health care.

\section{Methodological Procedure}

It is a case study with a qualitative approach, conducted between March and May 2014, in seven 
health centers of a municipality located in the metropolitan region of Belo Horizonte-MG. This choice is justified by the fact that the municipality has already implemented at the time of the research, the STM in all health centers. It is important to highlight that in each health center a family health team is allocated.

The inclusion criteria used for the composition of the sample were all the nurses, doctors and nursing technicians of the municipal PHC; be part of APS team. Regarding nurses, they had to be responsible for using the PHC and all of them have voluntary and free acceptance to participate in the study.

Of the total of twenty-six selected participants, 22 gave the interview. Among them, there were seven nurses (71.4\% female), four doctors (75\% male) and 11 nursing technicians (100\% female). Four interviews were not in effect, two from doctors, due to the transfer unit, and two nursing technicians, one because of the refusal and the other by successive misunderstandings.

Data were collected through semi-structured interviews, conducted individually, face-to-face, with a duration average of fifty minutes and in restricted areas to ensure the confidentiality of the participants. The statements were recorded in electronic devices and fully transcribed. The observation technique was also held that was developed exclusively for nurses, considering that the screening through the STM in the municipality is performed exclusively by professionals. The established observation period was three days for each unit, and the technical happened in the offices where the TRIUS (computers used by nurses to perform the screening) were allocated. The notes were recorded in a field diary, mentioning the description of events, people involved, dialogues, nonverbal behaviors, gestures as well as the impressions of the researcher.

The data were submitted to thematic content analysis proposed by Bardin [10], according to the three chronological divisions: pre-analysis of the material, exploitation and processing of results. The pre-analysis phase was based on the organization and floating reading material. After transcription, interviews were ranked according to the semi-structured guide. In the following phases, there was the exploration of the material with more insight and analysis of the results to be meaningful and valid. When the steps were completed, it was possible to make inferences and interpretations of the data, correlating them with the proposed objectives [10].

The study was approved by the Ethics Committee of the Federal University of Minas Gerais in opinion number 535,523 and the municipality of the study scenario. Participants signed the Informed Consent Form, according to Resolution 466/2012 of the National Health Council. To ensure anonymity, participants were named by codes: nurses (N); doctors (D) and nursing technicians (NT) and numbered according to the sequence of interviews.

\section{Results and discussion}

Analyzing the answers of the professionals, the ideas were organized into three categories of analysis: A) STM influences the daily life of professionals in primary health care; B) Hard technologies and soft technologies: a balance needed to provide care; C) The STM and the peculiarities of Primary Health Care.

\section{STM influences the daily life of professionals in Primary Health Care}

When asked about the influence of the STM in their daily work, participants mentioned first, the changes in their schedules. In the city, the professionals were asked to rank, all members of spontaneous demand in the STM. It should be noted that both the observation notes and the interviews enabled to identify interference in the pre-structured agenda, especially from nurses, who previously had greater availability and flexibility in meeting the demands. 
It finishes being together yes [the schedule], for example, in the morning that the flow is higher I cannot score anything, my schedule always have to stay for the afternoon. So sometimes the demand is higher, it becomes quite complicated.

[...] I had to reduce my schedule to attend the groups. I always I scheduled four smear tests in the morning, now I cannot anymore. I can only schedule two because it takes more time doing the screening.

Emerging reports during the period of observation revealed that the previous logic of organizing spontaneous demand, based on the hosting, understood in this context as a strategy to target patients according to their health needs, allowed nurses to organize schedules for performing childcare, prevention, prenatal care, home visits, among other activities related to the PHC proposal. However, after the implementation of the STM, the time devoted to these actions has been compromised, reflecting changes in the professional work process. Therefore, it is clear the disconnection between the health promotion and disease prevention and patients' services with acute complaints.

Therefore, it is considered that the challenge is to ensure adequate care for cases of spontaneous demand and scheduled demand without compromising the work process of professionals and ensure the recommended actions for PHC [11].

Regarding the application of STM, it is recommended by Ordinance number 2048 that the risk classification screening is performed by a health professional of higher education by specific training and use of protocols [12]. The study described by Coutinho et al. [13] signaled that the nurse performs a risk classification more properly, since the way physicians conduct the screening, eventually turning it into a moment of consultation and establishment of the diagnosis.

In this study scenario, it was possible to observe that all the screening process is carried out by nurses.

[...] I think that the health unit is not only hosting, I have prenatal to do. Can I do it in the afternoon? I can. But there are also only patient in the afternoon, and I have to do the screening.

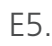

Nowadays it is very difficult for me to get out for visits, and it makes me very sad, because I get stuck attending headache, leg pain, ear pain, sore throat, I cannot go out to visit [...] because sometimes I was doing pre-natal, I knew it was only that, I would take long, I would guide, not now, I have to think that I cannot take more than forty minutes because suddenly I go out, I have the hosting, that to me does not exist.

The statements show that in addition to interfering in the activities already performed by nurses, the STM contributed to the increase in duties in health centers. This reinforces the impact on daily practices, since a single professional category is responsible for triage users and perform other recommended activities for the PHC. In this sense, a study conducted in the context of PHC in Belo Horizonte, before the implementation of the STM in the PHC of Minas Gerais, professionals were already concerned about the possible workload that such a tool could result [14].

\section{Hard technologies and soft technologies: a balance needed to provide care}

According to Merhy [15], the work on health is together with hard technological tools, soft-hard and soft, that the professional uses in his daily life to act in the process of interaction with the patient to provide care. In this regard, some professionals 
point out, in their statements, the importance of having the ability to recognize the needs of each patient, as their complaints may be related to a variety of problems such as unemployment, lack of leisure, loneness:

I think you can even use the Manchester, but you have to use your common sense as well because otherwise you will turn away a patient who will give a problem for us in the unit, have the patient's basic unit that is more common sense than Manchester.

In this perspective, NT8 statement shows the need to maintain a balance between the use of the STM and the use of soft technologies for the production of care. Soft technologies levied at the time of the relationship between the worker and patient meeting, establishing listening, interest, building bonds of trust, as strong evidence for the importance of living labor.

Living labor captures the uniqueness, the cultural world, specific ways of life of the patient and enriches and expands the clinical judgment of health workers [15]. Thus, it is understood that the STM can integrate everyday practices of $\mathrm{PHC}$, but for this, the professional needs to ensure the structural axis of this assistance point.

It is noteworthy that the demands of patients in the PHC are beyond the verbalized complaints and require professional a view fixed on subjective aspects related to social factors that are not solved with the use of medications and specific treatments [16].

In basic care it [STM] loses some contact, it will become more mechanized, if the person behind the machine cannot extrapolate beyond the machine, a person who does not know how to use the protocol, it will be restricted, and will miss things, the social part of primary health care, then we do not create our ultimate goal which is the bond.
N2 testimony refers to an interpretation of the STM as a physical barrier and at the same time as a machine that can become invisible. Regarding the physical barrier, the STM is used as hard technology, which can prevent the professional relationship and trust established with the patient in the care process. The possibility of STM invisibility come from the professional's ability to use it while extrapolating the machine and achieve a clinical reasoning mediated by soft technology, which considers the patients' subjectivity. Thus, it is recognized that for the use of STM there should be the articulation of the use of soft technologies for the production of care.

The work focused on soft and relational technology is essential to realize the living labor, because it establishes connections between professionals allowing for greater creativity in health care and enables productive relationships by meeting with the patient's singularities [17]. If the interaction between the team fails to happen, the act of health does not change and does not evolve.

The STM is considered a breakthrough in the Brazilian health system. However, to use it with resoluteness and accountability of PHC, it is essential that professionals and managers reflect on the health work process at this point of care. It is very important the appreciation of the hosting as a behavior, so that the professional can comply with what is recommended by the protocol and develop specific care plans, consistent with the reality of each patient and family.

Then I'm already apprehensive to soon receive the complaint because it has a queue waiting for me, there they are going to talk about the son, grandson and I do not have that time to listen, [...] then that's what's Primary Care, do not get attached to Manchester, the hour, the time controlling me. 
The hosting proposes a more resolute health care to be able to overcome the curative and fragmented care model. The hosting must go beyond listening something or someone attentively, and the professional and staff offer positive feedback and assist the population in their health needs. [18] Thus, the hosting can be understood as a powerful device reorganization of the production of care in PHC, to expand access to health services [4] and deconstruct a practice centered on prescriptive acting.

In a study by Kawata et al. [19] during the hosting with risk classification the professional remained focused on the patient. However, in this study, the professional recognizes the need for hosting together with the use of STM to provide better response to health needs through qualified listening.

[...] you have to listen to the complaint, it's the side of complaining of what he is feeling, but, unfortunately there are patients with their emotional side influencing more than the complaint, there are days, like what do you do? So I think it works [Manchester Protocol] in part, but if the nurse is human, she will also look at the other side of the patient, how do you do?

The NT8 testimony reinforces that health needs of patients in PHC are not limited to acute complaints. Moreover, he shows that professionals are attentive to listen to other demands as a way to strengthen the relationship and the consequent approach to the patient contributing to the outcomes of care [20].

Therefore, it is important to consider the subjects in a unique way to their wishes and aspirations, respecting their beliefs, values, to be more autonomous and co-participatory.
Manchester, it is a system that you do not need much to know the patient's history. You put the data, the patient's complaint, and it does not ask for history. In Primary Care we work not only with the complaint, but we also have to work with history, that's why we have records

In this perspective, the hosting is a viable strategy for qualified listening, indispensable for the professional and able to assume a posture of hosting, listening and agreeing more appropriate responses to the patients. This approach facilitates the process of working teams to organize, qualify and humanize care.

Thus, the STM can be understood as a necessary and useful tool. But when used as a single source of response to patients' needs, it becomes insufficient because it does not include subjective, affective, social and cultural aspects. Hard technologies incorporated by $\mathrm{PHC}$ must be designed and structured by the actions taken, and the objectives must achieve in each therapeutic project.

When placing the private activities of $\mathrm{PHC}$ in the background, the demand for the service is again influenced by the presence of the disease, for acute complaints, and thus the idea of comprehensive care and continued weakening.

Manchester is all day while you have a patient, you have to be there. So, sometimes she [nurse] fails to do preventive, she stops visiting, the visits it fell a lot, all this because of Manchester.

\section{The STM and the peculiarities of Primary Health Care}

This study revealed that the STM adapts it better to the reality of secondary care. A justification for this analysis is because that in the studied scenario, there are fixed opening hours of the units other than the emergency room that is open twenty-four 
hours. Thus, it becomes unenforceable to assist all users within the range of expected time.

It is not meant for primary care, it was not done for primary care, [...] it was made to emergency care, right? The very characteristics of it, when you establish those emergencies, it establishes service time, right? If my unit closes at 4 p.m. I will attend a patient 3.45 and the protocol tells me that he can expect certain hours, how come he can wait so many hours if the health center is being closed, you know?

The analysis also refers reflections regarding patients' access to the PHC. When the access is difficult due to the use of the STM, the hosting dialogues are fragile and difficult the closer link between the health unit and the community.

[...] the Manchester Protocol for me is very difficult for patients, patient care, the PSF patient is there to prevent the risk of disease contamination, is not for curative purposes and Manchester in my opinion it is for curative purposes.

It is noticed that the professional experience the tension between what should be done and what is being done effectively, because, while it welcomes the patient, it makes him wait for hours to be assisted or even schedule his service. The identified dilemma is that when there is the patients' triage and not guide him to care as a result of downtime, the professional is being inconsistent with the STM rules, endangering the life of the patient, as well as being against the ethical and legal principles governing the profession.

\section{[...] sometimes he has to schedule an appointment, he should be assisted in low hours, four hours and sometimes he has to wait one day, two days to his appointment, then it's still a little messy, it is a little out, but I think it will work over time.}

It is noteworthy that among the functions of $\mathrm{PHC}$, there is the patient's guidance in the care network that for Andrade et al. [21] it is recognized as a strategy to provide unrestricted health for patients. Professionals acting in PHC need to contribute so that patients have access to all levels of care. Thus, it is important that the professional knows the support systems in the health care network for the best referral for the patient [22].

However, professionals and local managers must have knowledge and clarity of the peculiarities and the actions taken in different parts of the care network, thereby using other mechanisms that include intrinsic aspects of the work process in $\mathrm{PHC}$.

Despite the rigidity of the STM, it was observed that the professionals are meeting the demands of the population. However, they state that the primary actions of health promotion, disease prevention and rehabilitation were compromised.

acute assistance, acute and chronic care are not good, we work with prevention, but it is not what happens today. Our goal was to work with prevention, but we know that we do not work, we are just firefighting, right?

Thus, it is understood that the use of STM promoted changes in practices and routines of professionals, which has hampered the continuity of care and interfered with the patient's access to the service. This reality reveals the need to rethink the applicability of this protocol in the PHC.

\section{Final considerations}

The implementation of the Manchester Triage System in Primary Health Care in the state of Minas Gerais was the result of a government management policy, which aims to improve the quality of care. In this study, nurses, professionals directly linked to the risk classification system, said the use of the protocol affected the relationship with the patient, 
qualified listening and the resolution demands that go beyond the diagnostic issues and discriminating listed by the STM.

It is essential that the classification is guided in the hosting, in listening, in being with "the other", and a moment of encounter, bond, and care. Therefore, it is essential that the timing of screening is set into an opportunity to humanized encounter and gather information that can support their full and continuous care. It is essential to articulate the use of hard and soft technologies in the work process for the production of care. Thus, professionals who use the STM must consider the subject of a singular and comprehensive way, turning their attention also to the subjectivity of the relationship with the patient, thinking of a qualified listening able to accommodate and meet the health needs.

A limitation of the study is the fact that professional only from one municipality of Minas Gerais have been investigated. Thus, more research was needed to contribute to the understanding of the applicability of the STM in the PHC and on the necessary adaptations to that assistance to urgencies and emergencies occur and resolution to reduce the influence on daily practices of professionals and ensure the continuous, comprehensive care to patients.

\section{Compliance with Ethical Standards}

We declare no conflict of interest.

This research involves human beings, respect the ethical principles and complies with the resolution 466/2012. Search Opinion: 535,523.

\section{References}

1. Matta GC, Morosini MVG. Atenção Primária à Saúde. In: EPSJV (Org.) Dicionário da Educação Profissional em Saúde. 1.ed. Rio de Janeiro: EPSJV, Fiocruz; 2009. Disponível em: <http://www. epsjv.fiocruz.br/dicionario/verbetes/ateprisau.html> Acesso em: 17 mar. 2015.

2. Brasil. Ministério da Saúde. Política Nacional de Humanização. Humaniza SUS. Brasília; 2004; 32 p.

3. Brasil. Ministério da Saúde. Acolhimento e Classificação de Risco nos Serviços de Urgência. Série B - Textos Básicos de Saúde. Brasília; 2009; 60 p.

4. Assis MMA, Nascimento MAA, Franco TB, Jorge MSB. Produção do cuidado no Programa Saúde da Família: olhares analisadores em diferentes cenários [online]. Salvador: EDUFBA; 2010; 180 p. ISBN 978-85-232- 0669-7. Disponível em: SciELO Books $<$ http://books.scielo.org > Acesso em: 17 mar. 2015.

5. Freitas LFC, Moreira DA, Brito MJM. A continuidade do cuidado na perspectiva do ser cuidado. Cogitare Enferm 2014 Out-Dez; 1(4): 694-700.

6. Brasil. Ministério da Saúde. Acolhimento à Demanda Espontânea. In: Cadernos de Atenção Básica; 2011; 60 p.

7. Soares S, Lima L, Castro A. O papel da atenção básica no atendimento às urgências: um olhar sobre as políticas. JMPHC. J Manag Prim Health Care 2014 jul; 5(2): 170-77. Disponível em: <http://www.jmphc.com/ojs/index.php/01/ article/view/214/147> Acesso em: 30 Jun. 2015.

8. Minas Gerais. Secretaria de Estado de Saúde de Minas Gerais. SES promove reunião para discutir Protocolo de Manchester; 2012. Disponível em: <http://www.saude.mg.gov.br/component/ gmg/story/3548-ses-promove-reuniao-para discutir-protocolode-manchester-sesmg> Acesso em: 20 mar. 2015.

9. Brasil. Ministério da Saúde. Acolhimento à Demanda Espontânea. In: Cadernos de Atenção Básica; 2012; II: 15-23.

10. Bardin L. Análise de conteúdo. São Paulo: Ed. 70; 2011; 229 p.

11. Scholze AS. Acolhimento com classificação de risco para a Estratégia Saúde da Família: a prática em uma unidade docenteassistencial. Ver Bras Med Fam Comunidade 2014; 9(31):21926, Disponível em: <http://www.rbmfc.org.br/rbmfc/article/ view/637> Acesso em: 17 mar. 2015

12. Brasil. Ministério da Saúde. Portaria $n^{\circ} 2.048$, de 05 de novembro de 2002. Propõe a implantação nas unidades de atendimento às urgências do acolhimento e da triagem classificatória de risco. Diário Oficial União. 05 de novembro de 2002. Disponível em: <http://www.saude.mg.gov.br/images/ documentos/portaria 2048 B.pdf>. Acesso em: 20 de julho de 2015. 
13. Coutinho AAP, Cecílio LCO, Mota JAC. Classificação de risco em serviços de emergência: uma discussão da literatura sobre o Sistema de Triagem de Manchester. Rev Med Minas Gerais 2012; 22(2): 188-98.

14. Torres HC, Lelis RB. Oficinas de formação de profissionais da equipe saúde da família para a gestão do acolhimento com classificação de risco. Cienc enferm 2010; 16(2): 107-13.

15. Merhy EE, Onocko R. Agir em Saúde: um desafio para o público. São Paulo-Buenos Aires: HUCITEC, 1997; 385p.

16. Santos TVC, Penna CMM. Demandas cotidianas na Atenção Primária: o olhar de profissionais da saúde e usuários. Rev Texto Contexto Enferm, Florianópolis 2013 Jan-mar; 22(1): 149-56,

17. Franco TB, Merhy EE. Cartografias do Trabalho e Cuidado em Saúde. Revista Tempus Actas de Saúde Colet 2012; 6(2): 151-63.

18. Carli R, Costa MC, Silva EB, Resta DG, Colomé ICS. Acolhimento e vínculo nas concepções e práticas dos agentes comunitários de saúde. Texto Contexto Enferm, Florianópolis Jul-Set 2014; 23(3):626-32.

19. Kawata LS, Mishima SM, Chirelli MQ, Pereira MJB, Matumoto S, Fortuna CM. Os desempenhos da enfermeira na saúde da família - construindo competência para o cuidado. Rev Texto Contexto Enferm, Florianópolis, Out-Dez 2013; 22(4): 961-70.

20. Frank BRB, Viera CS, Ross C, Obregón PL, Toso BRGO. Avaliação da longitudinalidade em unidades de Atenção Primária à Saúde. Rev Saúde Debate, Rio de Janeiro 2015; 39(105): 400-10.

21. Andrade AM, Brito MJM, Silva KL, Montenegro LC, Caçador BS, Freitas LFC. Organização das Redes de Atenção à Saúde na perspectiva de profissionais da atenção domiciliar. Rev Gaúcha Enferm 2013; 34(1):111-17.

22. Souza CC, Toledo AD, Tadeu LFR, Chianca TCM. Classificação de risco em pronto-socorro: concordância entre um protocolo institucional brasileiro e Manchester. Rev Latino- Am Enfermagem jan- fev 2011; 19(1): 26-33.

\section{Comment on this article:}
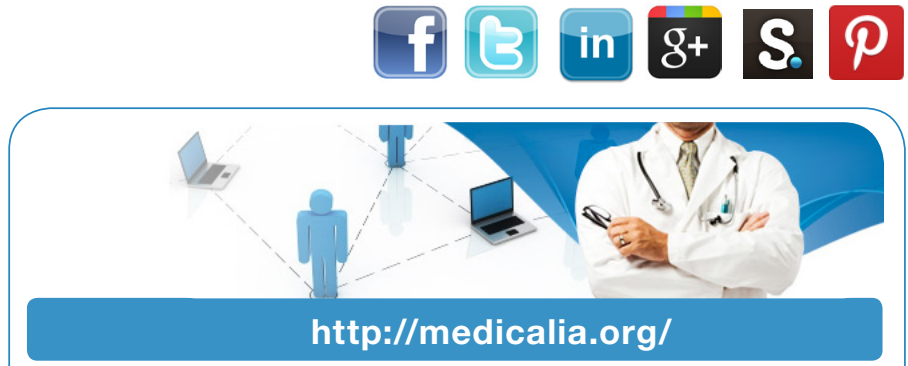

Where Doctors exchange clinical experiences, review their cases and share clinical knowledge. You can also access lots of medical publications for free. Join Now!

\section{Publish with iMedPub}

\section{http://www.imed.pub}

International Archives of Medicine is an open access journal publishing articles encompassing all aspects of medical science and clinical practice. IAM is considered a megajournal with independent sections on all areas of medicine. IAM is a really international journal with authors and board members from all around the world. The journal is widely indexed and classified Q1 in category Medicine. 